\title{
Factors associated with suicidal behaviour among depressed patients in Penang, Malaysia
}

Tahir Mehmood Khan¹, Syed Azhar Syed Sulaiman², Mohamed Azmi Hassali²

${ }^{1}$ College of Clinical Pharmacy, King Faisal University, Alahsa, Saudi Arabia ${ }^{2}$ School of Pharmaceutical Sciences, Universiti Sains Malaysia, Penang, Malaysia

Submitted: 5 October 2010

Accepted: 18 March 2011

Arch Med Sci 2012; 8, 4: 697-703

DOI: 10.5114/aoms.2012.28601

Copyright $\odot 2012$ Termedia \& Banach
Corresponding author:

Tahir Mehmood Khan MSc College of Clinical Pharmacy King Faisal University

Alahsa 400 Afoof Eastern Province Saudi Arabia Phone: +966-530610419 E-mail: tahir.pks@gmail.com

\begin{abstract}
Introduction: This study aims to highlight the factors associated with suicidal behavior among patients with depressive disorders.

Material and methods: A retrospective (Jan 2002 - Dec 2007) evaluation of medical records was done at the psychiatric clinic at the Penang (Malaysia) Public Hospital. Data was analyzed using Statistical Package for Social Science SPSS version $13^{\circ}$. Chi-square $\left(\chi^{2}\right)$ test was used to assess the association among variables. Odds ratios were calculated. Multiple logistic regression was applied to identify the predictors for suicidal behavior.

Results: Of 298 patients, 99 patients reported having thoughts of suicide. Overall, female respondents, particularly Chinese, constituted the majority reporting suicidal thoughts $(p=0.01)$. Cigarette $(p<0.01)$ and alcohol use $(p<0.01)$ were found to be associated with suicidal ideation. Among patients with medical comorbidities, diabetics were at a high risk for suicidal thoughts (odds ratio - $\mathrm{OR}=1.05,95 \%$ confidence interval $-\mathrm{Cl} 0.45-2.46)$. In terms of social problems, marital and relationship difficulties were the main risk factors $(\mathrm{OR}=2.03,95 \% \mathrm{Cl}$ : 1.16-3.58). The significant predictors for suicidal behavior were found to be smoking and alcohol use (adjusted $R^{2}=0.39, \mathrm{~F}$ change $=75.55, p<0.01$ ).

Conclusions: Chinese females were found at higher risk of suicidal ideation, as were smokers and alcohol users. The elderly aged 50 and over were also at a higher risk, followed by adolescents and youths aged 15-24 years. Comorbid medical complications and social problems were other factors that may contribute to suicidal ideation among the patients with depressive disorders.
\end{abstract}

Key words: suicidal behaviour, Penang Public Hospital, comorbidities, social problems, smoking and alcohol use.

\section{Introduction}

Depression with suicide attempts is a public health challenge around the world. The World Health Organization (WHO), 1996 has provided evidence that in the United States (US), more than 30,000 individuals commit suicide annually, and the estimated loss of productivity due to suicide is over $\$ 11.8$ billion [1-4]. Globally, it is estimated that one million suicides are recorded annually $[1,2]$. According to the WHO, suicides share the highest burden of intentional injuries in developed countries [5] and a massive increase in the suicide rate is expected in the coming decades $[6,7]$. In response to the anticipated elevation in the suicide rate, the WHO and the US government have been highly motivated to expand their 
knowledge on the incidence of and the factors associated with both fatal and non-fatal suicidal behaviour [2, 3, 8]. It is believed that such efforts will aid in the planning of public health policies in this regard $[2,3,8]$. While discussing the factors associated with suicide, one cannot ignore the mental disorders that pose a potential risk for suicidal behaviour and self-harm. Also, many studies have identified ethnic differences in the incidence of mental disorders and suicide [5], but very few researchers have considered the cultural epidemiology of self-harm. It is therefore essential to investigate the issue of suicide in diverse societies $[5,6]$, since culture does affect the rate and method of self-harming across countries [8-10]. Other factors playing a vital role in suicide rates include social segregation, unemployment, and financial strain $[1-4,11,12]$.

\section{Scenario in Malaysia}

Malaysia is a multicultural country, with an estimated population of 27 million. The population of Malaysia comprises Malays (Bumiputras), Chinese, Indians, and other minorities. A literature search revealed that Murungesan and Yeoh (1978) were the first to record the suicide rate in Malaysia [13]. They reported a high incidence of suicide among men, with an estimated male to female ratio of $2.9: 1$. Indians were found to have the highest rate of suicide, followed by the Chinese and Malays. However, other studies conducted in the year 1980 reported the male to female suicidal ratio to be $1: 2.8$ at the psychiatric ward at the Kuala Lumpur General Hospital [14]. Earlier studies reported a higher incidence of suicide among Indians, particularly among women [15-19].

The Malaysian Health Minister revealed in an interview that the estimated national average for suicide is 13 for every 100,000 people in the population, compared to just eight in the 1980s [20]. However, a senior consultant psychiatrist at the Hospital Universiti Kebangsaan Malaysia believes that this figure could actually be higher: "Due to various cultural, religious and legal prohibitions, suicides are grossly under-reported in Malaysia. Among Indians the estimated suicide rate is 30 to 35 in 100,000 compared with 15 Chinese and 6 Malays in every 100,000" [20].

According to the Head of Psychiatry Services at the Ministry of Health Malaysia, mental disorders, depression, emotional stress, relationship problems, anxiety, poverty, physical abuse, alcoholism, drug abuse, unemployment, and financial problems are possible risk factors for suicide in the Malaysian society. It has also been highlighted that men are four times as likely as women to successfully kill themselves. This is because men are less likely to seek help; they tend to employ more violent methods than women and are also more likely to abuse drugs and/or alcohol [20].

In a letter of intent, the Malaysian National Institute of Health [21] mentioned the unavailability of reliable and more recent data on the suicide rate in Malaysia. The earliest study in this regard was conducted in 1995 [19]. Afterward, there has been little information available. This study aims to provide the incidence of suicidal behaviour among depressed patients at the psychiatric Out Patient Department (OPD), public hospital Penang since there is no current or recent study that focuses on this area. Moreover, this study will also highlight the possible factors associated with suicidal behaviour.

\section{Material and methods}

This is a descriptive study based on retrospective evaluations of the medical records at the psychiatric Out Patient Department, public hospital Penang. Penang is one of the thirteen states and is geographically situated in northern Malaysia. It has an estimated multi-ethnic population of 1.5 million, comprising Malays (42.5\%), Chinese (46.5\%), Indians (10.6\%) and others (0.4\%) [22].

\section{Patients}

All registered patients medical records from January 2002 to December 2007 at the psychiatric Out Patient Department were reviewed. A total of 410 cases were registered during this time frame, of which 298 cases had a confirmed diagnosis of depressive disorders. Those cases with confirmed diagnosis of depression ( $n=298$ ) were considered for inclusion in this study. A data collection form was used to collate the information from the patients' records, such as socio-demographic data, family and personal medical history, comorbid medical complications, and types of symptoms reported. In case further information was required, patients on follow-up were also interviewed.

\section{Terminology and definitions in suicide research}

Standard definitions are used for terms such as "suicide" and "suicidal ideation" [23-25]. "Suicide" is defined as the act of intentionally ending one's own life, while "suicidal ideation" refers to thoughts of engaging in behaviour intended to end one's life. "Suicide attempt" refers to engagement in potentially self-injurious behaviour in which there is at least some intent to die $[26,27]$.

\section{Ethical considerations and statistical analysis}

The study protocol was approved by the Clinical Research Centre (CRC), Penang General Hospital, 
and the Ministry of Health, Malaysia. The data were analysed using the statistical software SPSS version $13^{\oplus}$. The data with quantitative variables were expressed in terms of mean ( \pm standard deviation - SD) and range while the qualitative variables were expressed as frequency and percentage. However, to further evaluate the association of race/ethnicity, gender, and age group with the incidence of suicidal ideation, a $\chi^{2}$ test was applied. Furthermore, odds ratios were observed, and multiple logistic regression was applied to identify the relationship predictors/risk factors (i.e. smoking, alcohol use, social problems and medical complications) that potentially contribute to subsequent suicidal thoughts $[1-4,11,12,20,47]$. Four models were defined. The first model determined whether there was a significant association between suicidal ideation and smoking. The second model examined the association between suicidal ideation and alcohol use. The third model evaluated the association between suicidal ideation and social problems (financial, job related problems, educational issues, relationship problems, childhood problems). The final regression model determined whether there is a potential effect of medical complications (renal dysfunction, relapse of depression, ischemic heart disease, gastritis, stroke, diabetes mellitus, hypertension) on the suicidal ideation. Goodness of fit for the models was tested using $R^{2}$, and overall level of statistical significance was checked through F-test by using suicidal ideation as a dependant variable. Values $\alpha$ less than 0.05 were considered significant.

\section{Results}

A total of 298 patient records were reviewed. The evaluation revealed that 99 patients reported having suicidal thoughts. Overall, the highest number of patients reporting suicidal thoughts were females, particularly Chinese $\left(\chi^{2}=12.18, \mathrm{~d} f=5\right.$, $p=0.01$ ), followed by Indians and Malays. Moreover, those disclosing cigarette smoking $\left(\chi^{2}=46.48\right.$, $\mathrm{d} f=1, p<0.01)$ and alcohol use $\left(\chi^{2}=73.29, \mathrm{~d} f=1\right.$, $p<0.01)$ were more likely to report suicidal ideation. Details on the association of demographics with suicidal thoughts are shown in Table I. Of the 99 cases, $16(15.2 \%)$ had made one or more suicide attempts. The majority, i.e. 12 (80.00\%), of these attempters were Chinese, followed by Malays (2 [13.30\%]) and Indians (1 [6.70\%]) (Table II).

\section{Risk factors for suicidal ideation}

Evaluation of the patients' medical records highlighted four possible risk factors for suicidal ideation: a) comorbid medical complications, b) social problems, c) smoking, and d) alcohol use. The data show that depressed patients with comorbid diabetes mellitus were at a high risk for suicidal thoughts (odds ratio $-\mathrm{OR}=1.05,95 \%$ confidence interval $-\mathrm{Cl} 0.45-2.46)$. Nearly all the patients had some social problems but those reporting marital and relationship problems were found to be at a higher risk $(O R=2.03,95 \% \mathrm{Cl} 1.15-3.56)$. However, those with a smoking habit $(\mathrm{OR}=7.10$, $95 \% \mathrm{Cl} 3.94-2.83)$ and alcohol use (OR $=3.69,95 \% \mathrm{Cl}$ 1.99-6.85) had the highest risk of suicidal ideation in comparison to others (Table III). To further clarify the predictors for suicidal behaviour, regression modelling was done using suicidal behaviour as the dependant variable and the four risk factors (comorbid medical complication with prevalence of depression, social problems, smoking and alcohol use) as the predictors. The significant predictors for suicidal behaviour were smoking and alcohol use (adjusted $R^{2}=0.39, p<0.01$ ) (Table IV).

\section{Discussion}

Research on the epidemiology of suicide has resulted in a number of conclusions. Global approximations have shown that suicide continues to be a leading cause of death, and it is possible that there will be a substantial increase in the numbers over the next several decades [28]. Similarly, the findings of the current study demonstrate a significant increase in the number of cases reporting suicidal ideation from the year 2002 to 2007 . The actual cause of this increase is still unknown, but it may be due to an increase in awareness among the public regarding suicide and suicidal ideation, resulting in a decline in the rate of underreporting. Another factor associated with underreporting may be the fact that the mental healthcare providers who assess psychiatric disorders use clinical diagnoses rather than standardised or validated assessment scales. The records demonstrated that a validated scale for the assessment of suicidal behaviour was only used in 35 (35.4\%) of the cases [29]. More patients may have been identified if a validated scale had been used to assess suicidal behaviour. However, further research needs to be conducted on this factor as a cause of underreporting of suicidal ideation.

\section{Nexus of demographic factors and suicidal ideation}

In the current study, the majority had reported suicidal ideation rather than suicide attempts. On ethnic grounds, Chinese were found to be at a high risk for suicidal ideation, followed by Indians and Malays. These findings contradict with the past findings that reported a higher incidence of suicide among Indians $[15,17,18,30]$. The factors responsible for this difference may be the population characteristics in the state of Penang, as the majority of the population residing in Penang Island are Chinese, followed by Malays, Indians, and others. An 
Table I. Demographic information on patients with and without suicidal ideation $(N=298)$

\begin{tabular}{|c|c|c|c|}
\hline Demographic information & $\begin{array}{l}\text { Suicidal ideation } \\
\qquad(n=99) \\
n(\%)\end{array}$ & $\begin{array}{l}\text { No suicidal ideation } \\
\qquad(n=199) \\
n(\%)\end{array}$ & Value of $p$ \\
\hline $\begin{array}{l}\text { Year } \\
2002 \\
2003 \\
2004 \\
2005 \\
2006 \\
2007\end{array}$ & $\begin{array}{c}1(8.3) \\
7(29.2) \\
11(18.3) \\
25(34.7) \\
20(40.8) \\
35(43.2)\end{array}$ & $\begin{array}{l}11(91.2) \\
17(70.8) \\
49(81.7) \\
47(65.3) \\
29(59.2) \\
46(56.8)\end{array}$ & $\begin{array}{c}\chi^{2}=14.51, \mathrm{~d} f=5 \\
p=0.01\end{array}$ \\
\hline $\begin{array}{l}\text { Gender } \\
\text { Male } \\
\text { Female }\end{array}$ & $\begin{array}{l}36(28.1) \\
63(37.1)\end{array}$ & $\begin{array}{c}92(71.8) \\
107(62.9)\end{array}$ & $\begin{array}{c}\chi^{2}=4.51, \mathrm{~d} f=2 \\
p=0.05\end{array}$ \\
\hline $\begin{array}{c}\text { Race/ethnicity } \\
\text { Chinese } \\
\text { Malay } \\
\text { Indian }\end{array}$ & $\begin{array}{l}61(84.7) \\
17(22.1) \\
21(42.9)\end{array}$ & $\begin{array}{l}11(15.3) \\
60(77.9) \\
28(57.1)\end{array}$ & $\begin{array}{c}\chi^{2}=12.18, \mathrm{~d} f=5 \\
p=0.01\end{array}$ \\
\hline $\begin{array}{l}\text { Age [years] } \\
\text { Median } \pm \text { SD } 46 \pm 16.8 \\
\text { Range } 15-84 \\
15-24 \\
25-30 \\
31-35 \\
36-40 \\
41-45 \\
46-50 \\
>50\end{array}$ & $\begin{array}{l}22(50.0) \\
11(45.8) \\
4(22.2) \\
9(33.3) \\
9(37.5) \\
12(30.8) \\
32(26.4)\end{array}$ & $\begin{array}{l}22(50.0) \\
13(54.2) \\
14(77.8) \\
18(66.7) \\
15(62.5) \\
27(69.2) \\
89(73.6)\end{array}$ & $\begin{array}{c}\chi^{2}=12.88, \mathrm{~d} f=7 \\
p=0.05\end{array}$ \\
\hline $\begin{array}{l}\text { Marital status } \\
\text { Single } \\
\text { Married } \\
\text { Widowed } \\
\text { Divorced }\end{array}$ & $\begin{array}{l}35(36.5) \\
48(27.9) \\
6(50.0) \\
10(55.6)\end{array}$ & $\begin{array}{c}61(63.5) \\
124(72.1) \\
6(50.0) \\
8(44.4)\end{array}$ & $\begin{array}{c}\chi^{2}=11.01, \mathrm{~d} f=5 \\
p=0.05\end{array}$ \\
\hline $\begin{array}{l}\text { Occupation } \\
\text { Not mentioned in record } \\
\text { Professional } \\
\text { Students } \\
\text { Stay at home only } \\
\text { Unemployed } \\
\text { Retired } \\
\text { Worker }\end{array}$ & $\begin{array}{l}16(42.1) \\
8(22.2) \\
17(47.2) \\
12(27.9) \\
3(37.5) \\
29(41.4) \\
14(20.1)\end{array}$ & $\begin{array}{l}22(57.9) \\
28(77.8) \\
19(52.8) \\
31(72.1) \\
5(62.5) \\
41(58.6) \\
53(79.1)\end{array}$ & $\begin{array}{c}\chi^{2}=9.41, \mathrm{~d} f=7 \\
p=0.22\end{array}$ \\
\hline Smokers & $64(64.6)$ & $35(35.4)$ & $\begin{array}{c}\chi^{2}=46.48, \mathrm{~d} f=1 \\
p<0.01\end{array}$ \\
\hline Alcoholics & $52(52.5)$ & $47(47.5)$ & $\begin{array}{c}\chi^{2}=73.29, \mathrm{~d} f=1 \\
p<0.01\end{array}$ \\
\hline
\end{tabular}

important issue in this regard is religion. Suicide is a prohibited act in Islam and virtually all Malays are Muslims, so we can assume that religion is one of the factors that prohibit Malays from thinking of or making a suicide attempt [31]. Moreover, the fear of psychiatric hospitalization, loss of face, and dishonour to their families may be other factors accounting for the low incidence or underreporting of suicide among Malays [20, 32].

The majority of Chinese and Indians are Buddhists and Hindus, respectively. Buddhism promotes the attitude among its believers not to commit acts such as taking one's life [33], while Chinese values do permit suicide in certain situations, such as to maintain honour and integrity [34]. Similarly, in Hinduism suicide is allowed in some cases, especially as an escape from present difficulties [35].

In addition to religion and ethnicity, one cannot ignore the other demographic factors, such as gender, age, martial status, and occupation. The records indicate that females were at a high risk, particularly Chinese females aged 50 years, followed by the age group of 15-24 years. Previous studies in this regard had reported a high incidence of suicide among Indian females aged under 30 years [7, 15, $18,30]$, but according to the recent facts, men were found four times more likely to commit suicide than women [20]. Our findings reveal the male to female 
Table II. Demographic information on patients who had made a suicide attempt

\begin{tabular}{|lcc|}
\hline Demographics & $N=15$ & Percentage \\
\hline Race/ethnicity & 12 & 80.00 \\
Chinese & 2 & 13.30 \\
Malay & 1 & 6.70 \\
Indian & & \\
\hline Gender & 2 & 13.30 \\
Male & 13 & 86.70 \\
Female & & \\
\hline Age [years] & 6 & 40.0 \\
15-24 & 3 & 20.0 \\
25-30 & 1 & 6.70 \\
31-35 & 1 & 6.70 \\
36-40 & 0 & 0.00 \\
41-45 & 2 & 13.30 \\
46-50 & 2 & 13.30 \\
\hline >50 & & \\
\hline Marital status & 9 & 60.00 \\
Single & 3 & 20.00 \\
Married & 1 & 6.70 \\
Widowed & 2 & 13.30 \\
Divorced & 10 & 66.70 \\
\hline Smokers & 6 & 40.00 \\
\hline Alcohol users & 1 & 6.70 \\
\hline History of medical complications & & \\
Hypertension & 3 & 20.00 \\
Diabetes mellitus & 2 & 13.30 \\
Gastritis & 1 & 6.70 \\
\hline Social problems & & \\
Relationship problems & 7 & 46.60 \\
Childhood problems & 1 & 6.70 \\
Financial problems & 1 & \\
\hline & & \\
\hline
\end{tabular}

ratio to be $1: 1.75$. Among young female patients aged $15-24$ years, educational and relationship problems were obvious complicating factors [20]. However, among the patients aged over 50 years, medical complications were observed to be a possible factor for depression which further leads to suicidal ideation $[16,17,40]$. The main medical complication proved to be diabetes mellitus; in other words, it can be assumed that those with diabetes mellitus were more likely to report suicidal ideation.
Table III. Medical and social history of patients with and without suicidal ideation

\begin{tabular}{|lcc|}
\hline Medical and social history & Odds ratio & $95 \% \mathrm{Cl}$ \\
\hline History of medical complications & & \\
Hypertension & 0.82 & $0.39-1.71$ \\
Diabetes mellitus & 1.05 & $0.45-2.46^{*}$ \\
Stroke & 0.59 & $0.06-5.80$ \\
Ischemic heart disease & 0.41 & $0.08-2.02$ \\
Gastritis & 0.98 & $0.32-3.05$ \\
Previous depressive episodes & 0.56 & $0.26-1.25$ \\
Renal dysfunction & 0.92 & $0.16-5.17$ \\
\hline Social problems & & \\
Marital/relationship problems & 2.03 & $1.15-3.56^{*}$ \\
Childhood problems & 3.32 & $0.72-5.17$ \\
Educational issues & 1.15 & $0.23-5.88$ \\
Job related problems & 0.57 & $0.16-2.09$ \\
Financial problems & 1.07 & $0.46-2.49$ \\
\hline Smokers & 7.10 & $3.94-2.83^{*}$ \\
\hline Alcohol use & 3.69 & $1.99-6.85^{*}$ \\
\hline *Significant p value less than 0.01, Cl-confidence interval
\end{tabular}

\section{Risk factors for suicidal behaviour}

Psychiatric disorders on the whole have been consistently reported as a risk factor for suicidal behaviour/ideation [36-39]. About 90-95\% of the people who die by suicide had some type of psychiatric disorder at the time of the suicide [40]. Those reporting low mood, poor impulse control, alcohol/substance use, and/or psychotic and personality disorders are at the highest risk for suicide and suicidal behaviour/ideation [27, 36, 38, 39, 4143], while the presence of multiple disorders is associated with an even more elevated risk [36, 37, 4345]. The present study revealed that diabetes mellitus, marital and relationship problems, smoking, and alcohol use are conspicuous potential risk factors for suicidal ideation. Regression modelling revealed the contribution of smoking and alcohol use to suicidal behaviour to be about $39.0 \%$ ( $p<0.01)$. The latest statistics of the use of alcohol and cigarettes in Malaysia revealed a total consumption of $12.7 \%$ of beer and about $0.70 \%$ avail-

Table IV. Predictors for suicidal ideation

\begin{tabular}{|lcccccc|}
\hline Model & $R$ & $R^{2}$ & Adjusted $R^{2}$ & FChange & Df & Significant F change \\
\hline 1 & 0.49 & 0.24 & 0.24 & 96.56 & $\begin{array}{c}\mathrm{d} f 1=2 \\
\mathrm{~d} f 2=295\end{array}$ & $<0.01$ \\
\hline 2 & 0.79 & 0.39 & 0.39 & 75.56 & $\begin{array}{c}\mathrm{d} f 1=2 \\
\mathrm{~d} f 2=295\end{array}$ & 0.65 \\
\hline 3 & 0.18 & 0.03 & 0.01 & 0.69 & $\begin{array}{c}\mathrm{d} f 1=6 \\
\mathrm{~d} f 2=290\end{array}$ & 0.73 \\
\hline 4 & 0.12 & 0.01 & -0.09 & 0.64 & $\begin{array}{c}\mathrm{d} f 1=5 \\
\mathrm{~d} f 2=291\end{array}$ \\
\hline
\end{tabular}

Dependant variable: Suicidal ideation. Model 1: predictors (smoking), Model 2: predictors (smoking and alcohol use), Model 3: predictors (social problems): financial, job related problems, educational issues, relationship problems, childhood problems, Model 4: predictors (medical problems): renal dysfunction, relapse of depression, ischemic heart disease, gastritis, stroke, diabetes mellitus, hypertension 
ability of alcohol drinks in Malaysia [46]. However, the overall incidence of smoking among Malaysians is about $31.40 \%$ and the majority among these are young men aged $15-30$ years [47]. Although it is difficult to draw any conclusions or associate any one factor with suicidal behaviour [32, 48, 49], our findings point to the need for a thorough screening of patients with depressive disorders and current smoking [50] and alcohol use.

In conclusion, the overall findings suggest that Chinese females are a higher risk group, both in terms of suicide attempts and suicidal behaviour. Smoking and alcohol use are central risk factors associated with suicidal behaviour. The elderly aged 50 years and over are at higher risk, followed by adolescents and youths aged 15-24 years. In addition to smoking and alcohol abuse, a history of medical complications and social problems are other factors that may contribute to suicidal ideation among patients with depressive disorders.

The small sample size is one of the main limitations of this study. Furthermore, this was a retrospective study it is possible that some information such as patient socio-economic and financial profile, clinical symptoms and other social or medical predictors that may help us in drawing a pin point conclusion were missed or not recorded in the medical records.

There is an immediate need to improve the management of patients' records at the psychiatric clinics in Malaysia. Certain demographic information, such as occupation, employment information, social issues, and income status, which may be helpful in uncovering the risk factors for suicidal ideation, are often missing in the medical records. The Ministry of Health Malaysia should link all the psychiatric healthcare settings through online software that covers all aspects, such as date of registration, diagnosis, types of symptoms reported, proposed therapy, suicidal thoughts, suicide attempts, follow-up, recovery, and default rate. This initiative would not only help the Ministry to get mental health updates in Malaysia but also help to design some strategies for the management of patients with suicidal ideation. Once patients with suicidal ideation are identified, community psychiatric care services can help in preventing suicidal attempts by such patients.

Randomised trials can be designed to further study the correlation between smoking and alcohol abuse on the one hand and suicidal attempts and suicidal ideation on the other. There is also a need to study the nexus of social, ethnic, and cultural issues with the incidence of suicidal behaviour. Finally, it would be more effective if future studies focus on the monthly rather than annual incidence of suicide, as such data may provide insights into the effects of seasonal, economic, or regional changes.

\section{References}

1. World Health Organization. Prevention of suicide: guidelines for the formulation and implementation of national strategies. Geneva: World Health Organization; 1996.

2. US Public Health Service. The Surgeon General's call to action to prevent suicide. Washington, DC: US Public Health Service; 1999.

3. US Department of Health and Human Services. Healthy People 2010. 2nd ed. With understanding and improving health and objectives for improving health (2 vols). Washington, DC: US Department of Health and Human Services; 2000.

4. Goldsmith SK, Pellmar TC, Kleinman AM, Bunney WE editors. Reducing suicide: a national imperative. Washington, DC: National Academies Press; 2002.

5. Mathers CD, Bernard C, Iburg KM, et al. Global burden of disease in 2002: data sources, methods and results. (Global Program on Evidence for Health Policy discussion paper no. 54). Geneva, Switzerland: World Health Organization; 2003.

6. Mathers CD, Loncar D. Projections of global mortality and burden of disease from 2002 to 2030. PLoS Med 2006; 3: e442.

7. Murray CL, Lopez AD, editors. The global burden of disease: a comprehensive assessment of mortality and disability from diseases, injuries, and risk factors in 1990 and projected to 2020. Cambridge, MA: Harvard University Press; 1996

8. World Health Organization. Suicide prevention (SUPRE). Geneva, Switzerland: World Health Organization; 2007. (http://www.who.int/mental_health/prevention/suicide/ suicideprevent/en/).

9. Chen PC, Lee LK, Wong KC, Kaur J. Factors relating to adolescent suicidal behavior: a cross-sectional Malaysian school survey. J Adolesc Health 2005; 37: 337.

10. Evans E, Hawton K, Rodham K, Deeks J. The prevalence of suicidal phenomena in adolescents: a systematic review of population-based studies. Suicide Life Threat Behav 2005; 35: 239-50.

11. NELMH: Suicide and Minority Ethnic People. [http:www.library.nhs.uk/ethnicity/ViewResource.aspx?resID $=111332 \&$ tablD $=290]$.

12. Burke AW. Socio-cultural determinants of attempted suicide among West Indians in Birmingham: ethnic origin and immigrant status. Br J Psychiatry 1976; 129: 261-6.

13. Murugesan G, Hock YO. Demographic and psychiatric aspects of attempted suicides-ninety-six attempts. Med J Malaysia 1978; 33: 102-12.

14. Haq SM, Buhrich N. Parasuicidal and their determinants in a multicultural society. Singapore Med J 1980; 21: 648-51.

15. Yeoh OH. Attempted suicides in Penang-preliminary observations. Med J Malaysia 1981; 36: 39-46.

16. Orr JW, Pu TN. Parasuicides in Kuala Lumpur. A descriptive study. Singapore Med J 1985; 26: 161-70.

17. Maniam T. Family characteristics of suicides in Cameron Highlands: a controlled study. Med J Malaysia 1994; 49: 247-51.

18. Maniam T. Changing pattern of suicide in Cameron Highland. Malaysian J Psychiatry 1994; 2: 48-58.

19. Habil MH. Health-seeking behaviour of depressed parasuicide patients in primary health care clinics. Asian Med J 1995; 21: 648-51.

20. Kaur M. Living dangerously. New Straits Times 2006 10 Oct; $10: 59$

21. National Insitutes of Health. A Study on the Risk Factors, Prevalence, Morbidity and Burden of Mental Illnesses at Various Levels (community, primary care etc.) in Malaysia. 
2007. HYPERLINK "http://www.nih.gov.my/LOI/MI/LOI2_2. php?id=MI"www.nih. gov.my/LOI/MI/LOI2_2.php?id=MI (accessed 20 February 2007).

22. Socio-Economic \& Environmental Research Institute (SERI) (2007) Penang Statistics, 2007 Quarter 2 page 3. [Online] accessed on 20th march 2008. available from World Wide Web http://www2.seri.com.my/Penang\%20Statistics/ 2007/Q2-April-June-2007-1.pdf

23. O'Carroll PW, Berman AL, Maris RW, Moscicki EK, Tanney BL, Silverman MM. Beyond the Tower of Babel: a nomenclature for suicidology. Suicide Life Threat Behav 1996; 26: 237-52.

24. Posner K, Oquendo MA, Gould M, et al. Columbia Classification Algorithm of Suicide Assessment (C-CASA): classification of suicidal events in the FDA's pediatric suicidal risk analysis of antidepressants. Am J Psychiatry 2007; 164: 1035-43.

25. Kirby M, Bruce I, Radic A, Coakley D, Lawlor BA. Hopelessness and suicidal feelings among the community dwelling elderly in Dublin. Irish J Psychologic Med 1997; 14: 124-7.

26. Nock MK, Prinstein MJ. Clinical features and behavioural functions of adolescent self-mutilation. J Abnorm Psychol 2005; 114: 140-6.

27. Nock MK, KesslerRC. Prevalence of and risk factors for suicide attempts versus suicide gestures: analysis of the National Comorbidity Survey. J Abnorm Psychol 2006; 115: 616-23.

28. Nock MK, Borges G, Bromet EJ, Cha CB, Kessler RC, Lee S. Suicide and suicidal behavior. Epidemiol Rev 2008; 30: 133-54.

29. Neeleman J, Jones P, Van Os J, Murray RM. Parasuicide in Camberwell-ethnic differences. Soc Psychiatry Psychiatr Epidemiol 1996; 31: 284-7.

30. Habil MH, Ganesvaran T, Agnes LS. Attempted suicide in Kuala Lumpur. Asia Pac J Public Health 1992-1993; 6: 5-7.

31. Hussain H, Hyman NW. Family Psychopathology and child hood experience of parasuicides admitted to university hospital, Kuala Lumpur. ASEAN J Psychiatry 1994; 4: 9-16.

32. Habil H. Parasuicide and suicide prevention programme an experience in Kuala Lumpur suicide prevention. New York: Plenum Press; 1998.

33. Ong S, Yeoh KL. Suicidal behaviour in Kuala Lumpur. Suicidal behaviour in the Asia pacific region. Singapore University Press 1978; 144-75.

34. Kok LP. Suicidal behaviour in Singapore. Suicidal behaviour in the Asia pacific region. Singapore University Press 1992; 176-98.

35. Venkoba Rao. History of Psychiatry in India. In: Howells G. editor. World History of Psychiatry. New York: Brunner/Mazel; 1975.

36. Nock MK, Borges G, Bromet EJ, et al. Cross-national prevalence and risk factors for suicidal ideation, plans and attempts. Br J Psychiatry 2008; 192: 98-105.

37. Kessler RC, Borges G, Walters EE. Prevalence of and risk factors for lifetime suicide attempts in the National Comorbidity Survey. Arch Gen Psychiatry 1999; 56: 617-26.

38. Mann JJ, Waternaux C, Haas GL, Malone KM. Toward a clinical model of suicidal behavior in psychiatric patients. Am J Psychiatry 1999; 156: 181-9.

39. Petronis KR, Samuels JF, Moscicki EK, Anthony JC. An epidemiologic investigation of potential risk factors for suicide attempts. Soc Psychiatry Psychiatr Epidemiol 1990; 25: 193-9.

40. Cavanagh JT, Carson AJ, Sharpe M, Lawrie SM. Psychological autopsy studies of suicide: a systematic review. Psychol Med 2003; 33: 395-405.
41. Shaffer D, Gould MS, Fisher P, et al. Psychiatric diagnosis in child and adolescent suicide. Arch Gen Psychiatry 1996; 53: 339-48.

42. Linehan MM, Rizvi SL, Welch SS, et al. Psychiatric aspects of suicidal behaviour: personality disorders. In: Hawton K, van Heeringen K, editors. International handbook of suicide and attempted suicide. 1st ed. Chichester, United Kingdom: John Wiley \& Sons; 2000; p. 147-78.

43. Shafii M, Carrigan S, Whittinghill JR, Derrick A. Psychological autopsy of completed suicide in children and adolescents. Am J Psychiatry 1985; 142: 1061-4.

44. Hawton K, Houston K, Haw C, Townsend E, Harriss L. Comorbidity of axis I and axis II disorders in patients who attempted suicide. Am J Psychiatry 2003; 160: 1494-500.

45. Shafii M, Steltz-Lenarsky J, Derrick AM, Beckner C, Whittinghill JR. Comorbidity of mental disorders in the postmortem diagnosis of completed suicide in children and adolescents. J Affect Disord 1988; 15: 227-33.

46. OECD and Malaysia Alcohol consumption 2007 [online] retrieved from http://micpohling.wordpress.com/2007/05/02/ oecd-and-malaysia-alcohol-consumption accessed on 21st October 2010.

47. Rampal L, Rampal S, Azhar MZ, editors. A National Study on the Prevalence and Factors Associated with Smoking among 17,246 Malaysians Aged 18 Years and above. The 13th World Conference on Tobacco OR Health Building capacity for a tobacco-free world. 2006 Jul 12-15, Washington, DC, USA.

48. Saroja KI , Kasmini K, Kyaw O. The detection of alcoholism in the general public hospital Kuala Lumpur. Malaysian J Psychiatry 1993; 1: 72-81.

49. Tsirigotis K, Gruszczynski W, Tsirigotis-Wołoszczak M. Indirect (chronic) self-destructiveness and modes of suicide attempts. Arch Med Sci 2010; 6: 111-6.

50. Kaddah S, Rashed L, Obaia E, Sabry D. A preliminary study: matrix metalloproteinase expression as an indicator of the hazards of shisha (nargila) smoking. Arch Med Sci 2009; 4: 570-6. 